\title{
A STRUCTURAL ANALYSIS OF THE SPERMATOPHORE OF RUNCINA FERRUGINEA KRESS (OPISTHOBRANCHIA : CEPHALASPIDEA)
}

\author{
ANNETRUDI KRESS \\ Department of Anatomy, University of Basel, Switzerland
}

\begin{abstract}
The spermatophore structure of the cephalaspid Runcina ferruginea is described. It is comprised of a central densely packed sperm mass surrounded by an inner layer of large globules and a thin outer layer, the capsule. The globules, which are formed in the prostate gland, seem to be lipid in character. Their possible function is discussed.
\end{abstract}

\section{INTRODUCTION}

A spermatophore is defined as a capsule of albuminous matter containing a number of sperm. Among opisthobranchs the families Retusidae, Philinoglossidae, Bullidae, Atydae and Runcinidae are all said to possess a copulatory apparatus which stores sperm and also forms spermatophores (Ghiselin, 1966). Relatively little information exists concerning the structure of the copulatory apparatus or the spermatophore in these groups and practically nothing is known about the copulatory behaviour of the animals and the fate of the spermatophore (Perrier \& Fischer, 1914; Ghiselin, 1963, 1966; Thompson, 1976; Beeman, 1977). This paper will focus on the structure of the spermatophore of the cephalaspid Runcina (Kress, 1977). The formation of sperm occurs in the hermaphroditic glands, in a more central position than that of the eggs. These autosperm leave via the common genital aperture which is located laterally to the gills. They travel by means of strong ciliary action, through a seminal groove to the male copulatory apparatus on the right of the mouth. The sperm then moves through the penis and the prostate into a storage sac, the seminal vesicle. For copulation, these sperm are packed into a spermatophore which should presumably be introduced into the common genital aperture but which may be found attached to the mantle or foot, even to animals not yet sexually mature. We have taken this opportunity to study the spermatophore which otherwise might not be easily detected.

\section{MATERIAL AND METHODS}

Specimens of Runcina ferruginea with spermatophores attached to foot or mantle were used.

\section{Light microscopy}

Specimens were fixed in Bouin and embedded in Paraplast and stained with HE and Pasini.

\section{Electron microscopy}

Specimens were fixed in $3^{\circ}{ }_{\circ}$ glutaraldehyde in $0.1 \mathrm{M}$ cacodylate buffer, with $12.5^{\circ}$, sucrose and $0.5 \% \mathrm{CaCl}_{2}$ added $(\mathrm{pH} 7 \cdot 2-7 \cdot 4)$. Specimens were then washed in $0.1 \mathrm{M}$ cacodylate buffer and postfixed in $1^{\circ}{ }_{0} \mathrm{OsO}_{4}$ in $0.1 \mathrm{M}$ cacodylate buffer $(\mathrm{pH} 7 \cdot 2)$ for $2 \mathrm{~h}$, dehydrated in acetone and 
embedded in Epon 812. Semi-thin as well as ultra-thin sections were cut on a Reichert OmU 2 ultramicrotome, stained with uranyl acetate and lead citrate and examined in a Philips 301 electron microscope. Semi-thin sections were stained with 1.4 phenyldiamine $1 \%$.

To detect glycogen, sections were treated according to the method of Thiéry (1967).

To identify the nature of the inclusions in the spermatophore, enzymes were used (Monneron \& Bernhard, 1966):

(a) Pronase as a proteolytic enzyme. Sections were placed for $30 \mathrm{~min}$ in $10 \%$ periodic acid and were then treated with $0.5 \%$ pronase at $37^{\circ} \mathrm{C}(\mathrm{pH} \mathrm{7.4})$ for 2,6 , and $18 \mathrm{~h}$.

(b) $\alpha$-Amylase for hydrolysis of glycogen. Sections were treated in $10 \%$ periodic acid followed by $0.5 \% \alpha$-amylase in $0.02 \mathrm{M}$ Sorensen buffer ( $\mathrm{pH} \mathrm{6.9)}$ for 6 and $18 \mathrm{~h}$.

To extract lipids, sections were exposed to xylene or methanol-chloroform (1:2) for 2, 4, or $6 \mathrm{~h}$.

\section{RESULTS}

The extruded spermatophores are minute, ovoid, with the attachment end tapered, whitish, $300-400 \mu \mathrm{m}$ in length and up to $240 \mu \mathrm{m}$ in diameter.

Light microscopy and semi-thin sections reveal a dense mass of tightly packed sperm, surrounded by a layer of strongly stained globules and a thin outer capsule (Fig. 1 A).

The spermatophore is surrounded by a $0.3-0.7 \mu \mathrm{m}$ thick outer layer, the capsule, which under electron microscopy is seen to be composed of an inner more fibrillar and an outer more flocculent structure, probably providing some stickiness for the attachment (Fig. 1 B). The inner layer consists of large, electron dense, membrane-bound globules, up to $10 \mu \mathrm{m}$ in diameter, with distinct internal lamellar structures (Figs. 1 C, 2 A, B). Interspersed among these globules, secretion and extrusions of the spermatophore-forming cells from the prostate gland can be found (Fig. 1C). Towards the centre lie the sperm, randomly orientated in a tight mass, sometimes separated by larger or smaller areas of electron dense material of irregular outline but without any lamellar structures (Fig. 1 C). The sperm exhibit extremely long, corkscrew-like heads and distinct glycogen deposits in their tails (Fig. 2D).

To identify the substances taking part in the formation of the surrounding spermatophore layers, the following tests were made:

$X y l e n e:$ after $2 \mathrm{~h}$ treatment there is a distinct extraction of material from the globules but these still show the lamellar structures (Fig. $2 \mathrm{C}$ ). After $6 \mathrm{~h}$ treatment only remnants of these globules remain.

Pronase: the structure of the capsule does not seem to be attacked by pronase after 2-6 h. The globules are still there but changed to a somewhat granular appearance with the lamellae still visible. The time may have been too short for a recognizable attack but longer exposure to pronase solution ruined the section completely.

$\alpha$-Amylase: exhibits no obvious effect on the capsule or the globular inclusions but causes total disappearance of glycogen from the sperm.

Thiery reaction for glycogen: the glycogen within the sperm reacts strongly positive (Fig. 2D) while neither the capsule nor the globular inclusions show any marked reaction.

Taking all these tests into account, the globules and their lamellae seem to be predominantly lipid in character. 

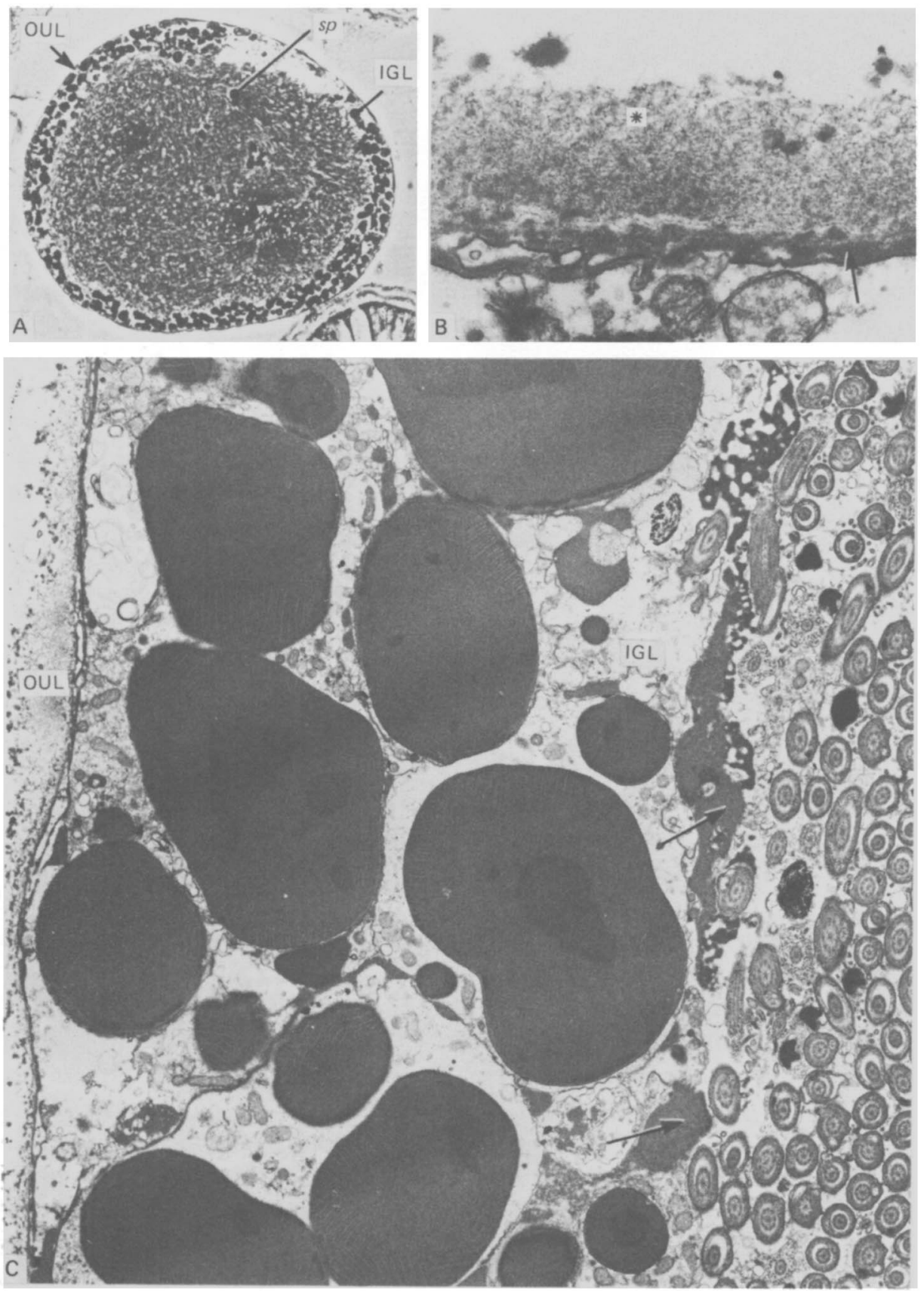

Fig. 1. (A) Semi-thin section of a spermatophore. sp, Sperm mass; IGL, inner globular layer; OUL, outer layer or capsule (arrow) $\times 320$. (B) Outer layer or capsule, consisting of a more fibrillar (arrow) and a more flocculent part (asterisk) $\times 37500$. (C) Section through the spermatophore showing the outer layer (OUL), the inner globular layer (IGL) with globules embedded in outer extrusion material from the prostate gland and part of the sperm mass. Electron dense material of irregular outline between the globules or sperms can also be seen (arrows) $\times 7500$. 

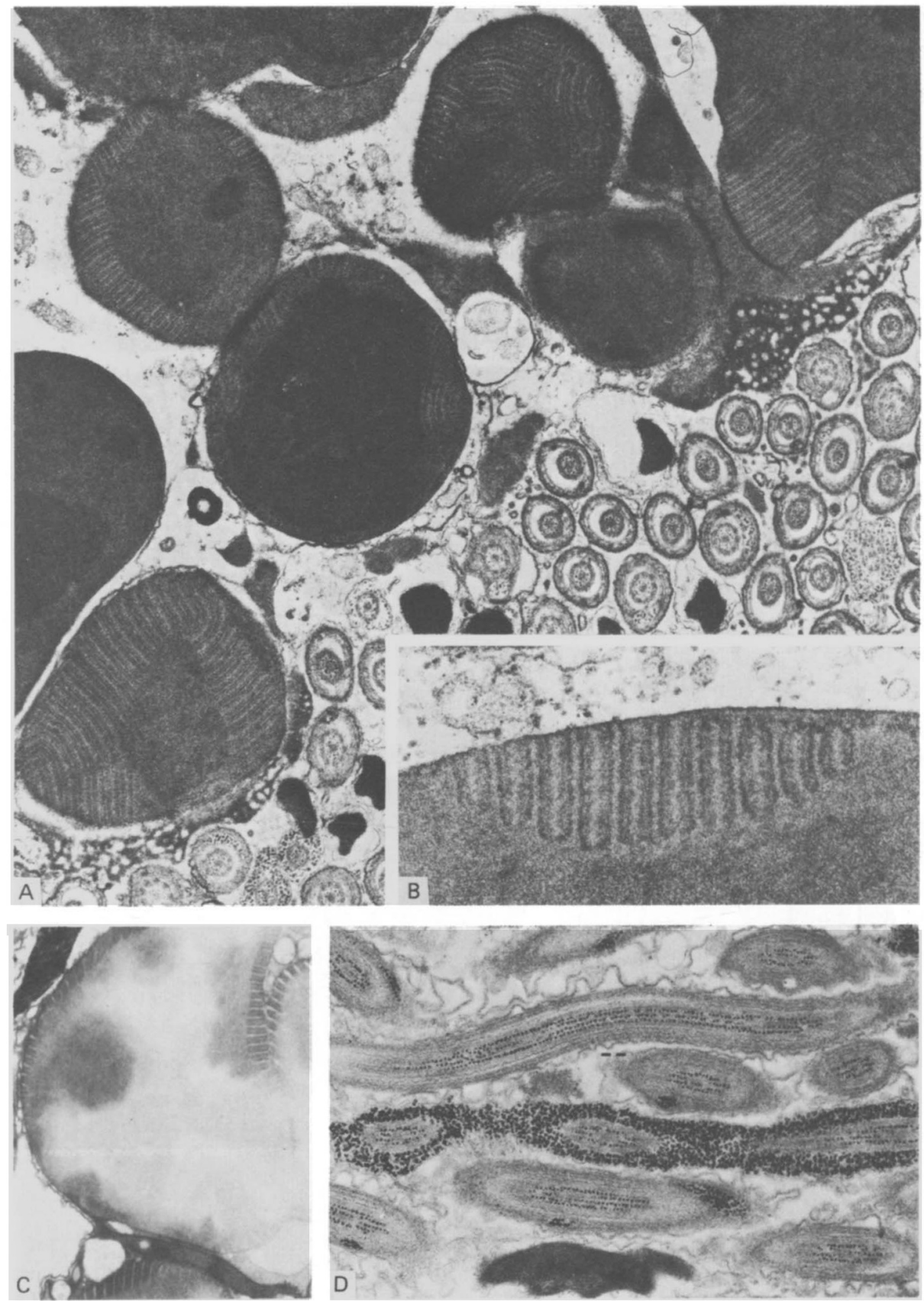

Fig. 2. (A) Higher magnification of globules demonstrating lamellar structure. $\times 13500$. (B) Inset. $\times 52500$. (C) Globules after treatment with xylene for $2 \mathrm{~h}$. Contents partly extracted but lamellar system still visible. $\times 9000$. (D) Section through sperm tails showing glycogen deposits. Thiéry reaction. $\times 14000$. 


\section{DISCUSSION}

The function of a spermatophore is to enable the transfer of sperm from male to female. In hermaphroditic opisthobranchs, cross-fertilization appears to be the general rule with a mutual exchange of semen accompanied by varying copulatory behaviour (Beeman, 1977). Ghiselin (1963) found that in Runcina the penis is inserted into the common genital aperture but does not penetrate deeply. Our finding of spermatophores attached randomly to the outside of Runcina specimens, raises the question whether these spermatophores gradually empty and the sperm penetrates the skin as described by Swedmark (1968) in acochlidiaceans. However, uncontrolled pathfinding by the exogeneous sperm is unlikely in view of the elaborately developed genital system. The external attachment may have occurred through a crowding effect in small ponds or jars.

While for gastropods and cephalopods no ultrastructural studies of spermatophores appear to exist, those of crustaceans have been better investigated (Malek \& Bawab, 1974 $a, b$; Uma \& Subramoniam, 1979; Kooda-Cisco \& Talbot, 1982; Dudenhausen \& Talbot, 1983). In the decapod Penaeus, Malek \& Bawab $(1974 a, b)$ describe two layers (I and II) around the main body containing the sperm mass, and three layers (III, IV and V) around a foliaceous accessory structure, the wing. Layers II, IV and V exhibit lipids in their composition, which is marked by its affinity to Sudan black B in contrast to layers I and III. The authors suggest that these layers render all parts of the spermatophore waterproof.

In Scylla (Uma \& Subramoniam, 1979) two distinct layers form a wall around the sperm mass. The outer one being thick and containing chitin, the inner one thin and rich in carboxylic groups. The wall structure allows entry of low molecular weight substances into the spermatophore, a fact which may be important after the deposition within the female genital tract. Two recently published ultrastructural papers describe the wall structure of spermatophores of the lobster and the crayfish, Pacifastacus. In both cases the sperm mass is surrounded by three acellular layers differing in composition and density and forming a thin capsule or wall. The outermost layer shows similarity with the outer wall structure of the Runcina spermatophore, being more fibrillar in character on its inner side and of more flocculent character on the outer side. If there is any hardening of this wall, as described for Scylla (Uma \& Subramoniam, 1979) or Pacifastacus (Dudenhausen \& Talbot, 1983), this could not be detected.

No recent description of crustacean spermatophores reports an inner globular layer of mainly lipid character and lamellar structure, as here described in the case of Runcina. The globules seem to be formed in the prostate (paper in preparation) but the exact role of this layer is not known. In contrast to the findings in the decapod Penaeus (Malek \& Bawab, 1974a,b), where lipids are incorporated into concentric layers surrounding the whole sperm mass, the loosely arranged globules in Runcina cannot have the same protective effect. It is possible that the lipid serves as an energy reserve, although Runcina sperm already 
contain a considerable amount of glycogen as described for other molluscs by Anderson \& Personne (1976). Since the fate of the deposited spermatophore is as yet unknown, it is difficult to speculate on the utilization of the lipids and where the necessary enzymes for this process would be located.

I wish to thank the Director of the Marine Biological Laboratory at Plymouth for providing working facilities and Mr J. E. Green of the Specimen Department for helping me to collect the animals. I am grateful to Mrs H. Schaller and Mrs T. Zmorski for their help with the light microscopy as well as to Mr G. Morson and Miss P. Roditscheff for their assistance in electron microscopy. I am indebted to Miss L. Serpell for her assistance with the preparation of the English Manuscript.

\section{REFERENCES}

Anderson, W. A. \& Personne, P., 1976. The molluscan spermatozoon: dynamic aspects of its structure and function. American Zoologist, 16, 293-313.

BeEman, R. B., 1977. Gastropoda: Opisthobranchia. In Reproduction of Marine Invertebrates, vol. IV (ed. A. C. Giese and J. S. Pearse), pp. 115-179. New York: Academic Press.

Dudenhausen, E. E. \& Talbot, P., 1983. An ultrastructural comparison of soft and hardened spermatophores from the crayfish Pacifastacus leniusculus Dana. Canadian fournal of Zoology, 61, 182-194.

GHiselin, M. T., 1963. On the functional and comparative anatomy of Runcina setoensis Baba, an opisthobranch gastropod. Publications of the Seto Marine Biological Laboratory, 11, 389-398.

GHISELIN, M. T., 1966. Reproductive function and the phylogeny of opisthobranch gastropods. Malacologia, 3, 327-378.

Kooda-Cisco, M. J. \& TAlBot, P., 1982. A structural analysis of the freshly extruded spermatophore from the lobster, Homarus americanus. Fournal of Morphology, 172, 193-207.

KRESs, A., 1977. Runcina ferruginea n.sp. (Cephalaspidea: Opisthobranchia: Gastropoda), a new runcinid from Great Britain. Fournal of the Marine Biological Association of the United Kingdom, $57,201-211$.

MaleK, S.R. A. \& BAwAB, F. M., 1974a. The formation of the spermatophore in Penaeus kerathurus (Forskal, 1775) (Decapoda, Penaeidae). I. The initial formation of a sperm mass. Crustaceana, 26, 273-285.

MaleK, S.R. A. \& BawaB, F. M., 1974b. The formation of the spermatophore in Penaeus kerathurus (Forskal, 1775) (Decapoda, Penaeidae). II. The deposition of the main layers of the body and of the wing. Crustaceana, 27, 73-83.

Monneron, A. \& Bernhard, W., 1966. Action de certaines enzymes sur des tissus inclus en Epon. fournal de Microscopie, 5, 697-714.

PERRIER, R. \& FisCHER, H., 1914. Sur l'existence de spermatophores chez quelques opisthobranches. Compte rendu hebdomadaire des séances de l'Académie des sciences, 158, 1366-1369.

Swedmark, B., 1968. The biology of interstitial mollusca. Symposia of the Zoological Society of London, no. 22, $135-149$.

ThIÉRY, J. P., 1967. Mise en évidence des polysaccharides sur fines en microscopie electronique. fournal de Microscopie, 6, 987-1018.

Thompson, T., 1976. Biology of Opisthobranch Molluscs, vol. I. 207 pp. London: Ray Society.

UMA, K. \& SUBRAMONiam, T., 1979. Histochemical characteristics of spermatophore layers of Scylla serrata (Forskal) (Decapoda: Portunidae). International fournal of Invertebrate Reproduction, 1, 31-40. 